\title{
STUDENTS' PERCEPTION OF COMPETENCIES DEVELOPED IN PRODUCT DESIGN EDUCATION WITH INDUSTRY INVOLVEMENT
}

\author{
Giovani Simão DE LUCA ${ }^{1,2}$ and Julio Carlos de Souza VAN DER LINDEN ${ }^{1}$ \\ ${ }^{1}$ Universidade Federal do Rio Grande do Sul - UFRGS \\ 2Universidade do Extremo Sul Catarinense - UNESC
}

\begin{abstract}
This paper presents the results of research developed at a university in the southern region of Brazil. Its product design college carries out design disciplines in partnership with companies, simulating a real environment for performing product designs. Based on the design competencies presented by Overbeek et al. (2004), this study observed which of the "core competencies" described by these authors have been developed throughout the projects conducted in partnership with companies. The study was developed in two stages and encompassed all levels of the course, which lasts four years. In this research, the "core competencies" were presented to the students who were asked to relate them to the disciplines where they think they developed better each competency, and also which were their perception of their level of mastery of that competency. Subsequently, the survey results were discussed in focus groups with teachers, as well as in groups of students. This study pointed out that the competencies of "User Focus and Perspective" and "Ideas + Concepts" were the ones more related to the activities with some kind of partnership with companies, while the competency "Market Orientation" did not have a relevant perception, opposed to what was expected. As a consequence of this study, a model will be proposed, as well as the continuation of these projects in an interdisciplinary way throughout disciplines in the following semesters, in order to make the "Market Orientation" competency better perceived in the product design college.
\end{abstract}

\section{Keywords: Design education, competency development, university-industry relationship}

\section{INTRODUCTION}

In developing countries, the main knowledge source that can lead to innovation are universities (Economic Commission for Latin America and the Caribbean [ECLAC], 2010, p. 33). At a time when speed in creating new products and services depends on sources of creativity beyond company boundaries, the collaboration between universities and companies becomes critical.

According to Perkmann and Walsh (2009) there are four types of collaborative projects that universities can develop together with companies: 1 - problem solving, which refers to advice on technical problems of $\mathrm{R} \& \mathrm{D}$, manufacturing or other business operations; 2 - technology development, which involves design or prototypes specification for new or incremental products and processes; 3 - testing of ideas, which explores a high-risk concept for the company, outside its regular activities; and 4 - knowledge generation, which deals with research on topics of great interest to companies.

The present study was developed in a university inserted in an industrial hub in southern Brazil where the interaction of the practical disciplines of design with the industries of the region is encouraged by the course coordinator. Along the seven years since the product design course beginning, several companies have established partnerships to develop technologies, testing of ideas and knowledge generation. It is a consensus among teachers, coordination, entrepreneurs, and students that the results of these partnerships are positive. Currently, the curriculum is distributed with projects in partnership with companies at all levels of the course, which lasts four years. Up to the fourth semester, they are made with low and medium complexity designs like decorative objects, toys and packaging. After the fifth semester, projects with more complexity as ceramic tiles, furniture and automotive design are made. These projects are in the type of technology development (2) and knowledge generation (4) according 
to the types of collaborative projects that universities can develop together with companies (Perkmann and Walsh, 2009). That is because all briefings start from early stages of design.

Some student solutions have already been industrialised, awarded and companies themselves confirm the positive return with projects that, as they affirm, could hardly be achieved internally without the collaboration of this product design course.

So far, the relations with industry had been evaluated from the perspective of students' interest, concerning scholarships that were given, the visibility brought to the course and to projects that continued with companies. Performing research that uses parameters of the designer's academic education to measure competencies development by students and reflect on the next steps to improve this relationship were the motivations for this research.

\section{THEORETICAL BACKGROUND}

From the need for a more precise measurement of parameters, similar experiences to this one were researched. Berge et al. (2002) define competencies as a set of interrelated principles that directly impact over the effective performance of a certain work, and can be measured, validated and improved through training and development. As measurement parameters, we used the competencies described by Overbeeke et al. (2004), where the authors present a curricular structure created with the objective of including real problems into disciplines that are integrated for its resolution. This study was selected as a reference because it was developed in a similar context of relation with the industry and presents competences that can be measured and analysed for better development of the curriculum.

Overbeek et al. (2004) describe the industrial design course from Eindhoven University of Technology (TU/e), where the students are considered "junior employees", allocated in groups of five students they receive an open challenge, monitored by a teacher-facilitator and the real client (industry) who serves as a reference throughout the project. All projects are aimed at developing some of the listed competencies and all of them integrate human, socio-cultural and technological aspects. These real projects are structured based on nine competencies of designers: 6 core competencies and 3 metacompetencies.

In this study, we chose to use the 6 core competencies, presented in Table 1, which can be directly related to the activities and disciplines of the undergraduate course.

Table 1. The 6 Core Competencies

IDEAS + CONCEPTS: Develop visions and innovative concepts through creativity techniques, experimentation and the translation of research.

INTEGRATING TECHNOLOGY: Proceeding from a sound technological and scientific background, can select and integrate concepts and technologies from different fields during all phases of the design process, up to and including the realisation of a prototype.

USER FOCUS AND PERSPECTIVE: Observe, analyse, empathise and interpret potential end user needs to create a successful product, system or service.

SOCIAL AND CULTURAL AWARENESS: Observe and analyse social behaviours and their cultural context in developing design applications for specific communities.

MARKET ORIENTATION: Construct a strategic viewpoint, which weighs the commercial opportunities of design concepts against existing and changing market sectors. This viewpoint enables the consumer-oriented positioning of products and services.

VISUAL LANGUAGE: Observe, develop and express a visual language, which connects thought and form, in order to communicate specific properties of the design concept.

Source: Adapted from Overbeek et al. (2004) 


\section{METHODOLOGY}

The study encompassed all levels of the course, which lasts four years (two semesters in each year and eight semesters in the course). Students who participated in this survey attended at least one semester of study in the current year.

The study was elaborated in three steps: $i$. self-assessment questionnaire for students of all levels in order to assess their perception concerning their competencies evolution; $i i$. focus group with teachers to discuss the questionnaire results; and iii. four focus groups with students separated by course level $\left(2^{\text {nd }}, 4^{\text {th }}, 6^{\text {th }}\right.$ and $8^{\text {th }}$ semesters $)$.

The questionnaire was elaborated with the purpose of identifying where the competencies were being developed and quantify them. As a starting point, we used the 6 core competencies cited by Overbeeke et al. (2004). The definition of each competency was presented in the questionnaire to facilitate their understanding by the student, followed by a space where the student could report the perception of course activities (or outside the course) in which this competency was developed and, finally, the degree of mastery of each competency was measured in a scale from 1 to 5 (1 - very low and 5 - very high). The questionnaire was answered online and in writing (printed form), without considering distinctions in the two modalities.

In addition to measuring the student progress level through the self-assessment, the importance of each academic activity for the development of the competencies was considered according to the number of appearances in the answers, that is, how many times a given activity was considered an important factor for the development of each competency.

From the analysis of the questionnaire, a focus group was conducted with teachers to assess whether the perception of students was shared by them, and in order to find explanations for the results presented. The session was held with the course coordination and 5 teachers who work in various disciplines and lasted 60 minutes.

Finally, in order to confirm the results obtained in the questionnaires and verify the teachers' perception, four focus groups sessions were held with students. They were carried out separately with students of each semester (approximately 6 participants in each) and lasted between 30 and 40 minutes. The mediator started with a slide presentation of the questionnaire results and, at the end of the presentation, they discussed with the participants if those results corresponded to what was experienced during classes.

\section{RESULTS}

\subsection{Questionnaire}

We obtained a total of 39 replies from all levels of the course, which corresponds to almost $50 \%$ of the total of students of the course (81 students). The respondents are distributed as follows: 8 students from the $2^{\text {nd }}$ semester; 9 students from the $4^{\text {th }}$ semester; 11 students from the $6^{\text {th }}$ semester; and 11 students from the $8^{\text {th }}$ semester. When students' answers contained more than one activity related to the competencies, these answers were considered separately. Figure 1 presents the relation of activities with the competency's development, emphasising those activities that presented more associations, and those with less association are placed in the group named "other".

Projects with companies were mentioned by a great part of the students in all competencies, demonstrating the scope that this kind of project reaches. We can also note that some competencies are more related to project activities with companies than others, "Ideas + Concepts" and "User Focus" stand out with a percentage of $60 \%$ of the relationships.

Surprisingly, the competency "Market Orientation" was not strongly related to company project activities in the answers. With a result of $38 \%$, it was recognised by a little more than one-third of the respondents. This result surprised the researchers because we supposed that as they work with real projects since the first years of the course, naturally the students would relate "Market Orientation" with these experiences. 


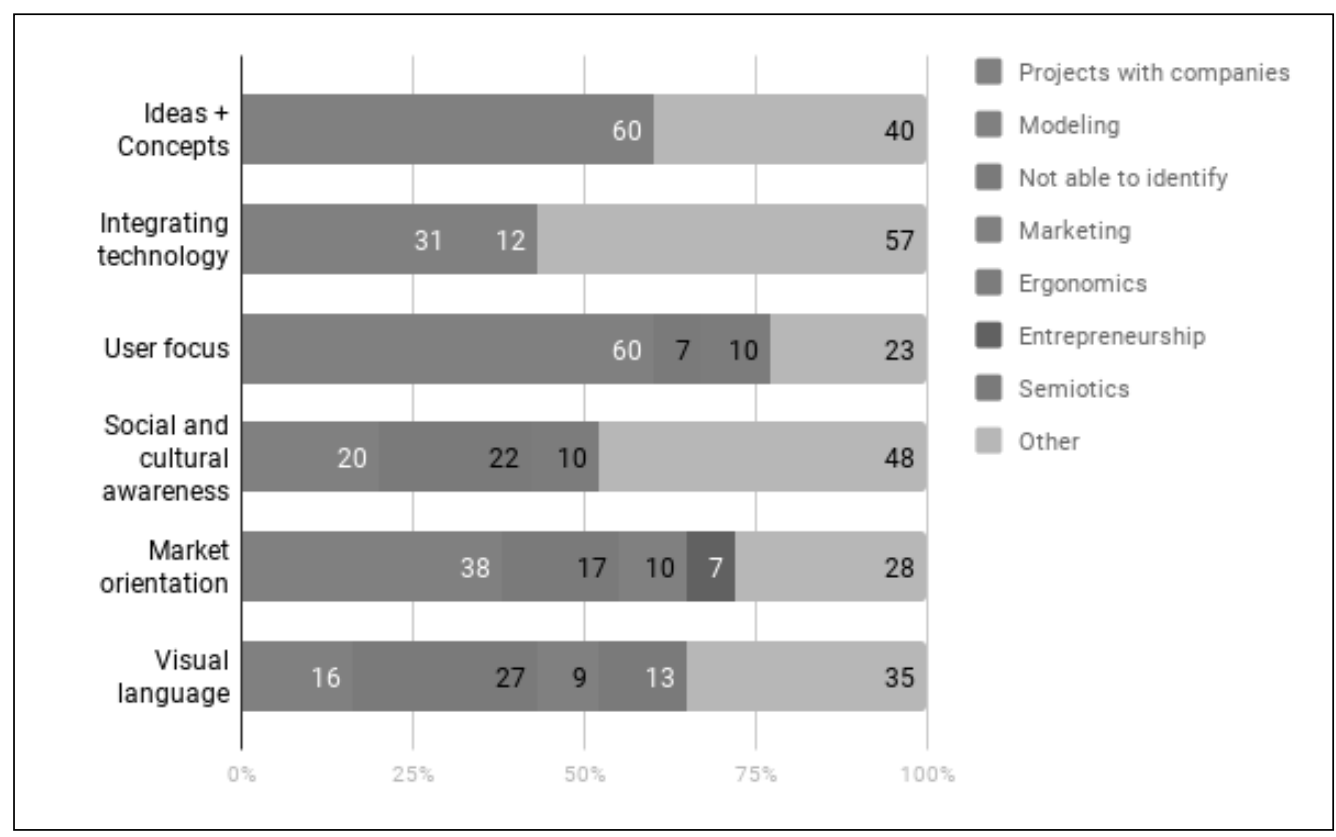

Figure 1. Relation of activities with the competency's development

In order to visualise the competencies evolution over the semesters, the means for the respective degrees of mastery assessed by the students were calculated. The means for each competency per semester are shown in Figure 2, where we can see that the values evolve over the semesters, showing that the educational curriculum is working on the development of the analysed competencies. Means of the means for each semester was calculated: $2^{\text {nd }}$ semester $M=2.23(\mathrm{SD}=0.60) ; 4^{\text {th }}$ semester $\mathrm{M}=3.15$ $(\mathrm{SD}=0.15) ; 6^{\text {th }}$ semester $\mathrm{M}=3.34(\mathrm{SD}=0.28)$; and $8^{\text {th }}$ semester $\mathrm{M}=3.71(\mathrm{SD}=0.27)$.

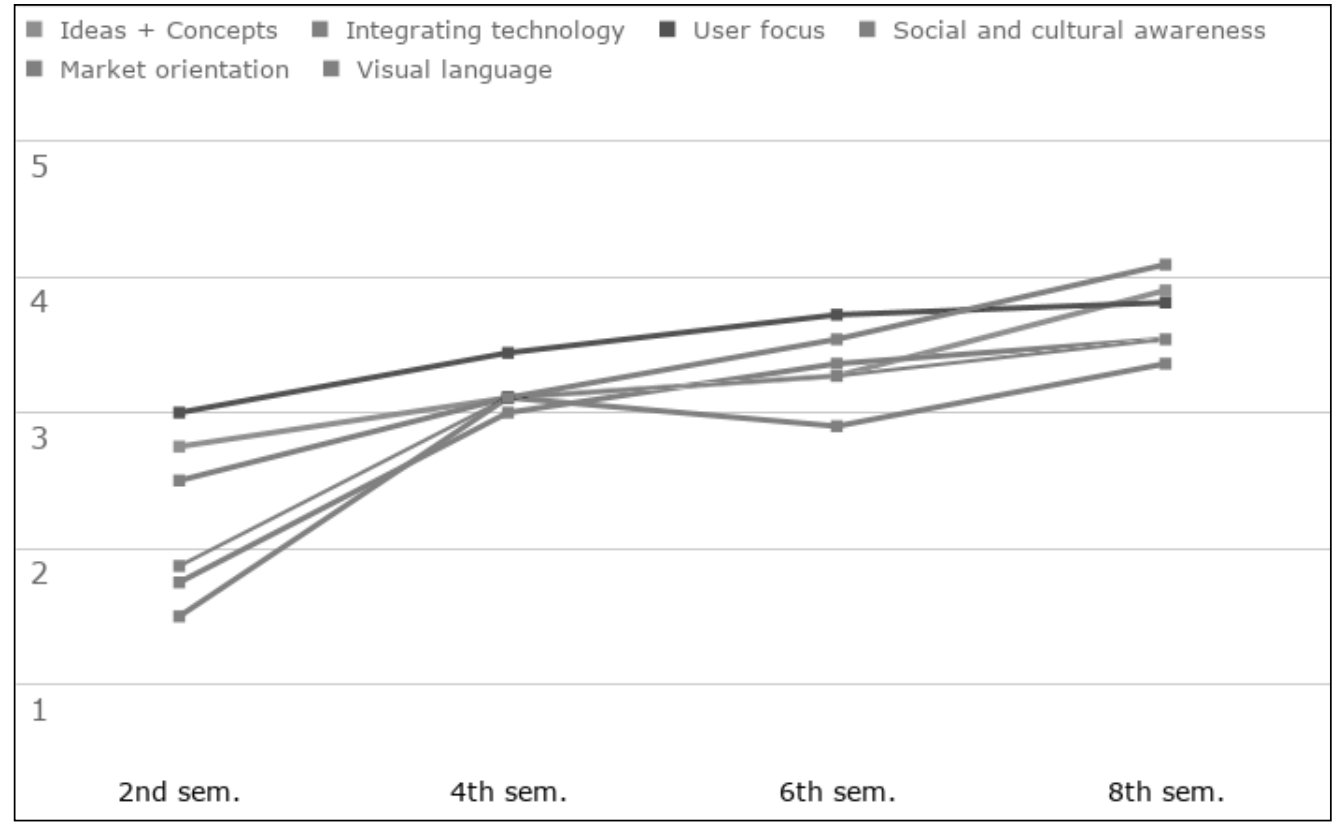

Figure 2. Competencies development

However, as seen in Figure 2, the "Market Orientation" competency (red line) is not as prominent as expected, with the smallest increase among them and the last among students in the $6^{\text {th }}$ and $8^{\text {th }}$ semesters. Although its mean can be considered as a moderate value, it surprises for not reflecting students experience in projects with the industry.

\subsection{Focus Group with teachers}

As a result of the focus group conducted with teachers, a difficulty reported based on their previous experiences with projects with companies relates to time. The perception of time in industries is different 
from that within the academia, usually, in the industry, the period for a project is longer while at the university, periods are limited to one semester. Some teachers stated that just having contact with the industry does not automatically mean that the "Market Orientation" competency is developing. Some suggestions such as having greater clarity between student and company expectations and greater freedom within briefings (e.g., choosing the target audience) may contribute to this improvement.

According to the course coordination, the development of the product engineering is not the main objective of the course and, perhaps, this is the reason why some competencies that are more connected to the concept and the user have developed more than the market orientation competency. Anyway, an idea raised to emphasise this competency is the continuity of projects with companies in other disciplines, such as product management and production management.

Finally, the discussion of competencies development within the course was pointed out as positive, and there was an agreement among teachers that the educational curriculum is working well due to the evolution observed between the self-assessment of beginning and concluding students. The competencybased assessment was also praised because it relates to the student and not necessarily associated with the teacher, which often makes the student relate the evaluation to the affinity with the teacher and not necessarily to learning. It was also discussed that this type of competency assessment can be applied to other courses with the appropriate selection of competencies for each area.

\subsection{Focus Group with students}

\subsubsection{Focus Group: Beginning Semesters}

The students from beginning semesters reported that the experience of sharing projects with companies was positive because they could practice what it was like to work with a "real client". This means that they have a higher demand for themselves and, consequently, the effort to deliver good work is higher. They regretted that many times, the contact with the company is indirect through the teacher, resulting in longer response times and scarcity of information for the project.

According to them, the smaller development of the "Market Orientation" competency comes from a very cautious treatment as academics, which causes errors to be revealed and the projects are not actually applicable. In general, they feel that these experiences are relevant mainly because they are able to better develop the research stage of the project.

\subsubsection{Focus Group: Final Semesters}

Among the students from the final semesters, some impressions signalised by the beginning students repeat. They gave a stronger emphasis to the treatment, agreeing that they cannot be requested as professionals but something in the middle of academic and professional because they feel that the demand of companies with respect to design errors ends up being very low. They see the feedback as a parameter to identify if those proposals really work in the market.

About the experience with companies as a whole, they said that at the beginning of the project the students are very motivated, and this motivation tends to decrease during the process when the company is not present. They suggested the implementation of a contract between the course and companies to determine briefing, production requirements, costs, time for mentoring, feedback format, etc. For good results, they emphasised the need for at least one meeting during the development process, because this would help point out errors that are too late to correct in the final presentation.

As an example, to reinforce the relationship with the companies, they cited some industries that have a more controlled process, where they can reach an advanced stage of prototyping. The student pointed out that when they cannot have the market vision in practical projects with companies, other disciplines such as Entrepreneurship end up supplying this need. The interdisciplinarity is positive according to them because they need to deliver projects for other disciplines, as part of the evaluation. They agree that approaching the projects already carried out in previous semesters under a new perspective can contribute to a greater development of the "Market Orientation" competency.

\section{CONCLUSIONS}

The experiences of projects in partnership with companies develop a comprehensive number of competencies for the product design students. This was confirmed both by the number of relationships between core competencies and projects with companies and by the reports in the focus groups. It has been suggested that the way in which the partnership is conducted defines which competencies are most 
valued by the students. In this specific Product Design course, the development of competencies is more related to conceptual design ("Ideas + Concepts" and "User Focus").

The present research emphasised the importance of interdisciplinarity with marketing and product engineering areas in order to continue the conceptual projects and complement students' profile with a more comprehensive view of the product development process.

The greater formalisation of the university-industry relationship in projects such as this proved to be important for students and teachers to visualise how far they can go and what the company can provide to get to what they need. This way, a virtuous circle is created where all parties win: teachers have practical examples and greater credibility in classes, entrepreneurs have new ideas and projects to launch and students practice how it is like to work as a product designer, with the advantage of having a followup at the university and "allow yourself to make mistakes".

As emerged from the focus group with the course coordinator and teachers, the lack of focus on "product engineering" does not explain why there is a lack of linkage to the 'market orientation'. Indicates that an integration with an industry, although extensive, is not yet deep.

In general, there are excellent prospects for the continuation of these projects in the future, but for that to happen, it is necessary to have: a clear vision of the product designer profile that is intended to form; continuous monitoring of competencies; reference model for teachers to follow; and adaptations in programmes of disciplines involved. According to this study, improvements such as these may cause the course to graduate professionals increasingly prepared for the challenges of the market. This reference model for university-industry integration will be developed and tested to continue this research.

\section{REFERENCES}

[1] Berge Z., De Verneil M., Berge N., Davis L. and Smith D. The increasing scope of training and development competency. Benchmarking: An International Journal, 2002, 9(1), 43-61.

[2] Cimoli M. (Coord.), Espacios iberoamericanos: vínculos entre universidades y empresas para el desarrollo tecnológico, 2010, 1, 50-52.

[3] Perkmann M. and Walsh K. The two faces of collaboration: impacts of university-industry relations on public research. Industrial and Corporate Change, 2009, 18(6), 1033-1065.

[4] Overbeeke K., Appleby R., Janssen Reinen I. and Vinke D. Nine competencies, six units: Industrial design education at TU/e. In Proceedings of International Engineering and Product Design Education Conference, E\&PDE'04, Vol. 1, Delft, September 2004, pp. 1-8 